\title{
Successful use of $i v$ diltiazem to control periopera- tive refractory complex atrial tachyarrhythmias in a patient with pneumoconiosis
}

\author{
[L'utilisation réussie du diltiazem iv dans le contrôle de tachyarythmies périopératoires, \\ auriculaires, réfractaires, complexes, chez un malade souffrant de pneumoconiose]
}

Chi-Hsiang Tsou MD, ${ }^{*}$ Chern-En Chiang MD PhD, $\dagger$ Jiing-Tarng Liou MD, $\ddagger$ Shi-Tai Hsin MD,$\ddagger$ Hsiang-Ning Luk MD MS PhD

\begin{abstract}
Purpose: To present a patient with pneumoconiosis who developed a complex, life-threatening atrial tachyarrhythmia during anesthesia. Intravenous diltiazem was effective in controlling the ventricular rate and hemodynamics after failure of other antiarrhythmic drugs and direct current cardioversion.
\end{abstract}

Clinical features: A 79-yr-old man with pneumoconiosis complicated by cor pulmonale suffered from gout-related cellulitis of the left lower limb. Debridement of the left gangrenous big toe was carried out under general anesthesia. During anesthesia, a wideQRS tachycardia occurred suddenly and a complex atrial tachyarrhythmia was later diagnosed. Hemodynamics deteriorated despite aggressive treatment with lidocaine, verapamil, direct current cardioversion, magnesium, digoxin and amiodarone. Correction of the underlying respiratory acidosis was not sufficient to control the rapid ventricular response. Eventually, iv diltiazem adequately controlled the rapid ventricular rate and quickly improved the deteriorating hemodynamics.

Conclusion: Life-threatening complex atrial tachyarrhythmias may occur in patients with chronic lung diseases perioperatively. Intravenous diltiazem was effective in the management of complex atrial tachyarrhythmia in a patient with underlying cor pulmonale.

Objectif : Présenter un patient atteint de pneumoconiose chez qui
s'est développée une tachyarythmie auriculaire grave et complexe
pendant l'anesthésie. Le diltiazem intraveineux a permis de contrôler
le débit ventriculaire et l'hémodynamique après l'échec d'autres
médicaments antiarythmiques et de la cardioversion. Éléments cliniques : Un homme de 79 ans, atteint de pneumoconiose compliquée d'un cœur pulmonaire, souffrait de cellulite reliée à la goutte au membre inférieur gauche. Le débridement du gros orteil nécrotique a été réalisé sous anesthésie générale. Pendant l'anesthésie, une tachycardie à onde QRS de forte amplitude est survenue soudainement et a conduit au diagnostic de tachyarythmie auriculaire complexe. L'hémodynamique s'est détériorée malgré un traitement agressif comprenant : lidocaïne, vérapamil, cardioversion, magnésium, digoxine et amiodarone. La correction de l'acidose respiratoire initiale n'a pas suffi à contenir la réaction ventriculaire rapide. Finalement, le diltiazem iv a permis de contrôler adéquatement l'accélération du débit ventriculaire et d'améliorer rapidement l'hémodynamique.

Conclusion : De graves tachyarythmies auriculaires complexes peuvent survenir pendant une opération chez des malades souffrant d'affections pulmonaires chroniques. L'administration intraveineuse de diltiazem a permis de traiter une tachyarythmie auriculaire complexe chez un patient atteint de cœur pulmonaire sous-jacent.

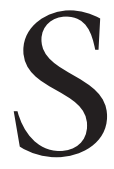

UPRAVENTRICULAR and ventricular arrhythmias are not uncommon in patients with chronic obstructive lung disease. ${ }^{1,2}$ The in-hospital morbidity and mortality rates are determined by several factors and mostly associated with a history of coronary artery disease, tachycardia and poor ventricular function. ${ }^{3}$ We present a patient with pneumoconiosis and cor pulmonale who developed an intractable and complex, life-threatening atrial tachyarrhythmia perioperatively. The $i v$ infusion of diltiazem proved to be effective.

From the Departments of Respiratory Therapy* and Cardiology, $†$ Taipei Veterans General Hospital and National Yang-Ming University, Taipei; and the Department of Anesthesiology, Chang Gung Memorial Hospital, Taoyuan, Taiwan.

Address correspondence to: Dr. Hsiang-Ning Luk, Associate Professor, Department of Anesthesiology, Chang Gung Memorial Hospital,

No 5, Fu-Hsin Street, Kwei-Shan Hsiang, Taoyuan, Taiwan. Phone/Fax: 886-3-328-3110; E-mail: luk1015@adm.cgmh.org.tw Accepted for publication July 10, 2002.

Revision accepted October 17, 2002. 


\section{Case report}

A 79-yr-old male was scheduled for the debridement of a left gangrenous big toe. The patient was being treated with antibiotics for possible septicemia due to goutrelated cellulitis. The past history revealed that the patient had been a coal miner for more than 35 years. Prior to this admission, pneumoconiosis and past pulmonary tuberculosis were diagnosed at a local clinic. The patient claimed that he had received a full treatment with anti-tuberculosis drugs. Exertional dyspnea (American Thoracic Society Scale: grade III) with pedal edema was progressive. He had been a heavy smoker for more than 50 years ( 2 packs/day), although he had stopped smoking for ten years. The patient was neither diabetic nor hypertensive but had suffered from gout for several years. Preoperative laboratory assessment revealed leukocytosis (white blood cells: $18500 \cdot \mathrm{mm}^{3}$ ), elevated C-reactive protein: $20.2 \mathrm{mg} \cdot \mathrm{dl}^{-1}$, normal range: $<0.8 \mathrm{mg} \cdot \mathrm{dl}^{-1}$ ), hyperbilirubinemia (serum total bilirubin: $2.3 \mathrm{mg} \cdot \mathrm{dl}^{-1}$; normal range: $0.2-1.6$ ), prolongation of the activated partial thromboplastin time (APTT; $40.5 \mathrm{sec} v s$ control $27.9 \mathrm{sec}$ ), a low platelet count $\left(140000 \cdot \mathrm{mm}^{3}\right)$. Temperature was normal. A chest $x$-ray revealed typical features of pneumoconiosis and past pulmonary tuberculosis. The preoperative complete 12-lead electrocardiogram (ECG) displayed sinus rhythm, incomplete left bundle branch block and atrial premature depolarization (APD) with aberrant conduction (Figure 1).

Before the operation, the patient was fasted for eight hours and no premedication was given. Intraoperative monitoring included an ECG, pulse oximetry, noninvasive blood pressure and end-tidal $\mathrm{CO}_{2}$. Before induction, blood pressure was $154 / 110 \mathrm{mmHg}$ and the ECG monitor showed atrial fibrillation (Af) with rapid ventricular response (110-120 beats. $\left.\mathrm{min}^{-1}\right)$. Due to prolongation of APTT and possible septicemia, general anesthesia was preferred. Anesthesia was induced with propofol (1.5 $\left.\mathrm{mg} \cdot \mathrm{kg}^{-1}, i v\right)$, succinylcholine $\left(2 \mathrm{mg} \cdot \mathrm{kg}^{-1}, i v\right)$ and fentanyl $\left(2 \mu \mathrm{g} \cdot \mathrm{kg}^{-1}\right)$ after a five-minute pre-oxygenation. A laryngeal mask (\# 4.0) was placed. Manual ventilation was adequate with $\mathrm{FIO}_{2} 100 \%$, although airway pressure was increased $\left(35 \mathrm{~cm} \mathrm{H}_{2} \mathrm{O}\right)$. Anesthesia was maintained with isoflurane in oxygen. The entire surgical procedure lasted $45 \mathrm{~min}$. The total amount of $i v$ fluid administered during the operation was $700 \mathrm{~mL}$ (lactated Ringer's solution). Intraoperative blood loss was negligible. No significant changes in blood pressure and heart rate were observed during the maintenance of anesthesia.

During emergence from anesthesia, the laryngeal mask was removed and replaced by a facial mask to assist ventilation. Unexpectedly, the patient awoke abruptly, manifested cold sweating and air hunger.

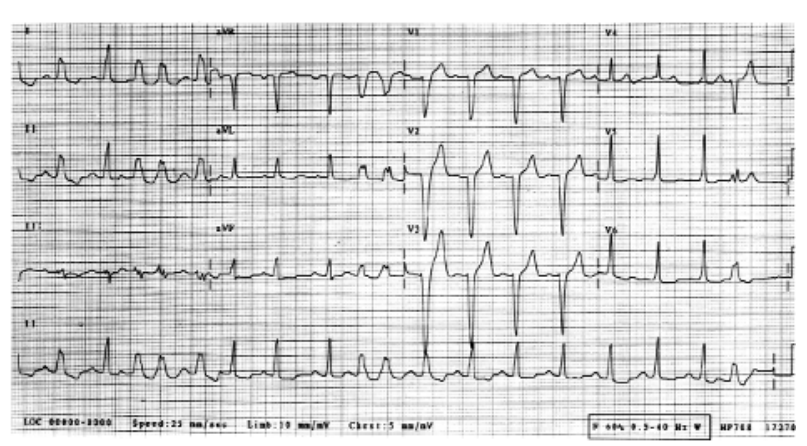

FIGURE I Preoperative electrocardiogram. Sinus rhythm, incomplete left bundle branch block, multiple atrial premature depolarizations with aberrant conduction, and poor $\mathrm{R}$ wave progression in the precordial leads are shown. Due to a rapid transition from a negative wave in V3 to a large positive wave in V4 (less likely an old anteroseptal myocardial infarction), a slightly broad $\mathrm{R}$ wave $(0.01 \mathrm{sec})$ and loss of septal $\mathrm{Q}$ wave in left precordial leads, incomplete left bundle branch pattern is diagnosed.

Urgent blood gas analysis revealed respiratory acidosis $\left(\mathrm{pH} 7.159, \mathrm{PO}_{2} 203.9 \mathrm{mmHg}, \mathrm{PCO}_{2} 75.8 \mathrm{mmHg}\right.$, base excess (BE) -1.8 mM, $\mathrm{K}^{+} 5.4 \mathrm{mM}$, ionized $\mathrm{Ca}^{2+}$ $0.94 \mathrm{mM}$ ) and the ventilation rate was increased to correct the acidosis. At the same time, wide-QRS tachycardia with a ventricular rate of $150-200$ beats. $\mathrm{min}^{-1}$ was noted (Figure 2A). Blood pressure was still stable $(158 / 72 \mathrm{mmHg})$. Lidocaine $\left(1 \mathrm{mg} \cdot \mathrm{kg}^{-1}\right.$, iv) was administered twice, but was ineffective in converting the rhythm. After detailed examination of the ECG, supraventricular tachycardia with aberrant conduction and multifocal atrial tachycardia (MAT) were highly suspected. Therefore, verapamil $(3 \mathrm{mg}, i v)$ was given in titration. It was still not effective. Although the followup gas analysis revealed that respiratory acidosis had been corrected via manual hyperventilation $(\mathrm{pH} 7.4$, $\mathrm{PO}_{2} 74.1 \mathrm{mmHg}, \mathrm{PCO}_{2} 40.0 \mathrm{mmHg}, \mathrm{BE}-0.1 \mathrm{mM}, \mathrm{K}^{+}$ $4.0 \mathrm{mM}$, ionized $\mathrm{Ca}^{2+} 0.74 \mathrm{mM}$ ), the rapid ventricular response persisted $\left(170\right.$ beats. $\left.\mathrm{min}^{-1}\right)$. The patient was sent to the postanesthesia care unit (PACU) for further treatment. In the PACU, due to the deteriorating hemodynamic status as manifested principally by hypotension $(50 / 30 \mathrm{mmHg})$, direct current cardioversion ( 50 joules) was applied after administration of lidocaine $(50 \mathrm{mg}, i v)$. Meanwhile, sodium bicarbonate and calcium gluconate were supplemented based on blood gas analysis data $\left(\mathrm{pH} 7.270, \mathrm{PO}_{2} 74.0 \mathrm{mmHg}, \mathrm{PCO}_{2}\right.$ $38.0 \mathrm{mmHg}, \mathrm{BE}-8.2 \mathrm{mM}, \mathrm{K}^{+} 3.98 \mathrm{mM}$, ionized $\mathrm{Ca}^{2+}$ $0.76 \mathrm{mM})$. Magnesium sulfate ( $1 \mathrm{gm}, i v)$ was infused 


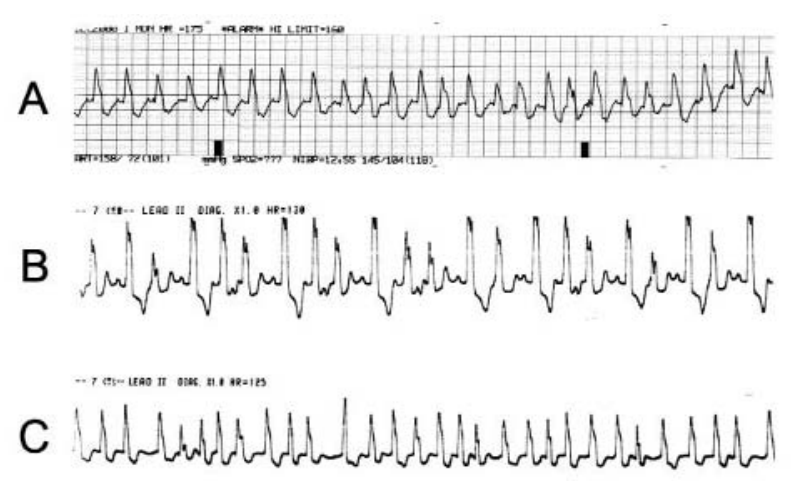

FIGURE 2 Serial electrocardiogram changes during perioperative period. A) wide-QRS tachycardia with a ventricular rate of 175 beats $\mathrm{min}^{-1}$. The initial impression was a ventricular tachycardia, but supraventricular tachycardia with aberrant conduction was diagnosed. B) sinus tachycardia with frequent couplets of atrial premature depolarizations after cardioversion $\left(130\right.$ beats $\left.\cdot \mathrm{min}^{-1}\right)$. C) atrial fibrillation with rapid ventricular rate (125-160 beats. $\mathrm{min}^{-1}$ ) after $i v$ infusion of amiodarone.

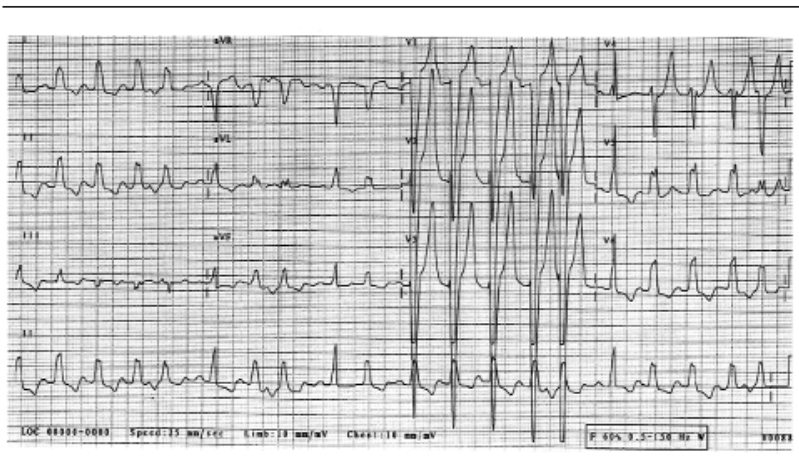

FIGURE 3 The electrocardiogram after $i v$ infusion of diltiazem. Sinus rhythm, frequent atrial premature depolarizations, complete left bundle branch block, and a slower ventricular rate (115-120 beats. $\mathrm{min}^{-1}$ ) are shown.

slowly and the rhythm was converted to sinus tachycardia with occasional short-runs of atrial tachycardia (Figure 2B). Subsequently, iv amiodarone $(300 \mathrm{mg}$, iv for ten minutes, followed by $900 \mathrm{mg} \cdot$ day $^{-1}$ iv infusion) was administered in order to control the atrial arrhythmia. However, the rhythm reversed to Af with rapid ventricular response (160 min, Figure 2C). The sustained rapid ventricular response was associated with persistent hypotension $(80 / 60 \mathrm{mmHg})$ and the need

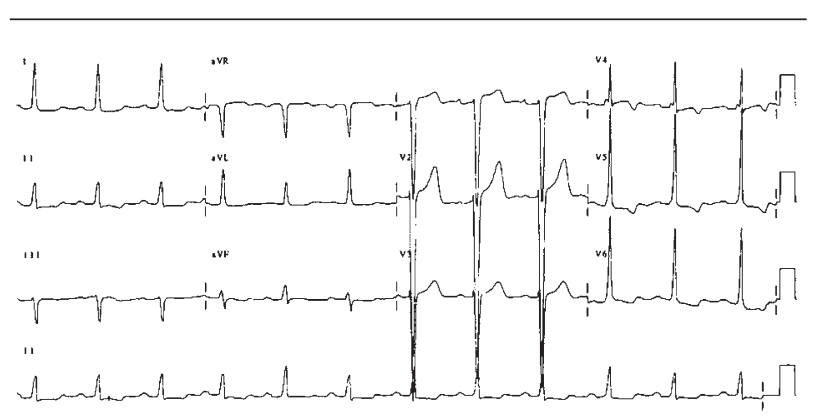

FIGURE 4 Follow-up electrocardiogram taken two weeks after the episode. Sinus rhythm (72 $\mathrm{min})$ is seen. Diltiazem was tapered off and oral amiodarone (200 mg, po, every day) was administered for maintenance.

to decrease ventricular rate was imperative. We administered diltiazem $(20 \mathrm{mg}$, $i v$, for $15 \mathrm{~min}$ ) as a last resort. Eventually, sinus rhythm resumed with short-runs of atrial tachycardia but the ventricular rate was slower (115-120 min; Figure 3). Acid-base imbalance was corrected $\left(\mathrm{pH} 7.4, \mathrm{PO}_{2} 100 \mathrm{mmHg}, \mathrm{PCO}_{2} 34 \mathrm{mmHg}\right.$, $\mathrm{BE}-1.7 \mathrm{mM}, \mathrm{SaO}_{2} 98 \%$ at $\mathrm{FiO}_{2} 40 \%, \mathrm{~K}^{+} 3.96 \mathrm{mM}$, ionized $\left.\mathrm{Ca}^{2+} 0.82 \mathrm{mM}\right)$. The patient's blood pressure became stable $(120 / 60 \mathrm{mmHg})$ and he recovered consciousness. The entire episode of rapid ventricular response lasted for four hours before it could be effectively controlled.

Transthoracic echocardiography performed three days later showed a dilated left ventricle and akinesis of the anterior ventricular septum and inferior wall with moderate left ventricle dysfunction. The ejection fractions of the left and right ventricles were $32 \%$ and $28 \%$, respectively. Holter monitoring (24-hr) revealed sinus rhythm, frequent APD with aberrant conduction. Pulmonary function tests showed a combined obstructive and restrictive ventilatory defect with severe reduction of diffusion capacity based on the following data: total lung capacity (TLC): $3.55 \mathrm{~L}, 63 \%$ of predicted value; residual volume/TLC: $61 \%, 158 \%$ of predicted value; forced expiratory volume in first second $\left(\mathrm{FEV}_{1}\right)$ : $0.98 \mathrm{~L}, 42 \%$ of predicted value; diffusion capacity of carbon monoxide (DLCO): 7.99 $\mathrm{mL} \cdot \mathrm{min}^{-1} \cdot \mathrm{mmHg}^{-1}$. Edema of the legs, exertional dyspnea and desaturation after exercise were also noted. Coronary artery disease could not be ruled out, although no elevation of cardiac enzymes, such as creatine kinase, $\mathrm{MB}$ fraction and troponin I was found. 
These findings were suggestive of pneumoconiosis with cor pulmonale and atrial tachyarrhythmias. His atrial arrhythmia was controlled by low dose amiodarone (200 $\mathrm{mg}$, po, every day) in the postoperative period (Figure 4).

\section{Discussion}

We present a case of perioperative refractory, complex and life-threatening atrial tachyarrhythmia in a patient with pneumoconiosis, in whom only iv diltiazem displayed efficacy in controlling the rapid ventricular rate and improved the deteriorating hemodynamics.

The incidence of arrhythmias is variable in patients with chronic obstructive lung diseases. ${ }^{1,3}$ Various factors are potentially arrhythmogenic, such as hypercapnia, acid-base imbalance, hypokalemia, digitalis, methylxanthines, $ß$-adrenergic agonists, aerosol propellants, steroids, ethanol, coronary heart disease, and cor pulmonale. The presence of ventricular arrhythmias in patients with chronic obstructive pulmonary disease (COPD) is thought to be associated with high in-hospital mortality and pedal edema, elevated $\mathrm{PCO}_{2}$, and masculine gender are predictors of repetitive arrhythmias in chronic lung diseases. ${ }^{3,4}$ However, history of coronary heart disease, increased sinus heart rate and decreased maximum work load rather than arrhythmias per se are predictors of death. ${ }^{3}$ In addition to ventricular arrhythmias, several types of supraventricular tachyarrhythmias may occur in patients with COPD, such as MAT, Af and flutter $(\mathrm{AF}) .{ }^{2}$ In this patient, the exact mechanism responsible for the arrhythmias observed is not clear. The later stage of pneumoconiosis is usually complicated by cor pulmonale and therefore the incidence of arrhythmias is increased. Our patient presented with signs of exertional dyspnea and pedal edema. Since the patient suffered from wound infection with possible septicemia, this condition might further predispose him to the danger of atrial arrhythmias. It has recently been demonstrated that systemic inflammatory response syndrome and sepsis are independent risk factors for the development of atrial tachyarrhythmias. ${ }^{5-7}$ During induction and maintenance of anesthesia, sympathetic stimulation and hypercapnia could also precipitate the preexisting arrhythmia into MAT and Af, eventually, resulting in intractable rapid ventricular response and impending tachycardia-induced heart failure.

Atrial tachyarrhythmias, although not necessarily lifethreatening, may cause thromboembolism, compromise of cardiac output, tachycardia-induced heart failure and poor quality of life. Although invasive radiofrequency catheter ablation has been demonstrated to be effective in certain types of atrial tachyarrhythmias, ${ }^{8,9}$ medical treatment is still the mainstay of therapy. In patients with atrial tachyarrhythmias, rate control should be placed before rhythm control. ${ }^{10,11}$ Thus, pharmacological agents that depress conduction and prolong refractoriness of the atrioventricular (AV) node are frequently required for the control of symptoms and improvement of hemodynamics during Af before the use of other antiarrhythmic agents capable of converting the rhythm. Paradoxical acceleration of the ventricular rate has been reported when patients with atrial tachyarrhythmias are treated with rhythm-control agents such as quinidine, propafenone, or even amiodarone, without having received AV node blocking agents. This situation also happened in our patient. Amiodarone paradoxically accelerated his ventricular rate (Figure 2C). Moreover, amiodarone should be used with caution in patients with decreased diffusion capacity, such as in this patient with pneumoconiosis. It is known that the incidence of amiodarone-induced pulmonary toxicity is about $5.8 \% .{ }^{12}$ The risk factors of pulmonary toxicity include advanced age, higher amiodarone maintenance dose, and lower DLCO. ${ }^{12,13}$ Although amiodarone may be safely used in patients with heart failure and COPD, ${ }^{14}$ short-term use of amiodarone can still cause acute or fatal pulmonary toxicity. ${ }^{12,15,16}$ It should also be noted that the outcome of long-term use of oral amiodarone in patients with pneumoconiosis with cor pulmonale remains to be evaluated.

Drugs that prolong refractoriness and decrease conduction velocity in the AV node include digoxin, $ß$-adrenergic antagonists, magnesium and calcium channel blockers. The electrophysiological actions of digoxin on the AV node are principally indirect and depend on cardiac innervation. Furthermore, the onset of its therapeutic effect is slow, at least $60 \mathrm{~min}$ after administration in most patients, with the full effect taking place in up to six hours. Therefore, iv digoxin was not the first choice to control the rapid ventricular response in this patient. Although B-blockers are now indicated in patients with compensated congestive heart failure, only chronic oral use of either one of the three $B$-blockers (metoprolol, bisoprolol, and carvedilol) is proven to be effective in patients with chronic stable heart failure. Intravenous B-blocker treatment is not a standard therapy in congestive heart failure. In this patient, left and right ventricular ejection fractions were $32 \%$ and $28 \%$, respectively. In addition, although cardioselective $\beta$-blockers could be used in the patients with mild to moderate reversible airway diseases, their effects in severe COPD or during exacerbation are inconclusive at this moment. In this patient, pulmonary function test showed $\mathrm{FEV}_{1}$ was only $0.98 \mathrm{~L}$ ( $42 \%$ of predicted value), TLC was 
$3.55 \mathrm{~L}$ (63\% of predicted value) and RV/TLC was $61 \%$ ( $158 \%$ of predicted value). The findings suggested a moderate to severe combined obstructive and restrictive ventilatory dysfunction. In addition, diffuse wheezing was noted perioperatively. Therefore, iv esmolol was not considered in this patient, although it is effective in converting postoperative supraventricular tachyarrhythmias. ${ }^{17-19}$

Magnesium did not prove to be effective in this patient, although it can be useful for COPD-related MAT. $^{20,21}$ Oral verapamil is not absolutely contraindicated in patients with congestive heart failure. However, $i v$ verapamil has a potent negative inotropic effect, excluding this agent from the list of rate controlling drugs in patients with congestive heart failure. ${ }^{22}$ Initial use of verapamil $(3 \mathrm{mg}, i v)$ was ineffective in this patient and later it was not supplemented because of deteriorating hemodynamics. According to the recently published advanced cardiac life support guideline, diltiazem, with its mild depressive effect on left ventricular function, can be used safely in conditions such as our patient's. ${ }^{22}$ An $i v$ bolus dose of diltiazem (20-25 mg) resulted in a slowing of the ventricular rate in $\mathrm{Af}$ or $\mathrm{AF}$ in one multicentre study. ${ }^{23}$ The median time to therapeutic response was four minutes, and a continuous infusion of diltiazem $\left(10-15 \mathrm{mg} \cdot \mathrm{hr}^{-1}\right)$ could maintain a good control of ventricular rate. Intravenous diltiazem effectively achieved short-term control of heart rate. ${ }^{24}$ This treatment is particularly useful in patients with COPD complicated with supraventricular tachyarrhythmias which are triggered or exacerbated perioperatively. However, this advantage may be offset by a higher incidence of hypotension in critically ill patients with atrial tachyarrhythmias. ${ }^{25}$ It should be noted that more controlled clinical trials are needed to evaluate the optimal pharmacological management of Af in seriously ill patients. ${ }^{26}$

In summary, we report the case of a patient with pneumoconiosis complicated by cor pulmonale and biventricular dysfunction, who developed complex lifethreatening atrial tachyarrhythmias perioperatively. Early accurate ECG diagnosis of the arrhythmia was obtained and $i v$ diltiazem was effective in the treatment of the otherwise refractory atrial tachyarrhythmias.

\section{References}

1 Corazza LJ, Pastor BH. Cardiac arrhythmias in chronic cor pulmonale. N Engl J Med 1958; 259: 862-5.

2 Holford FD, Mithoefer JC. Cardiac arrhythmias in hospitalized patients with chronic obstructive pulmonary disease. Am Rev Respir Dis 1973; 108: 879-85.

3 Shih HT, Webb CR, Conway WA, Peterson E, Tilley B, Goldstein $S$. Frequency and significance of cardiac arrhythmias in chronic obstructive lung disease. Chest 1988; 94: 44-8.

4 Hudson LD, Kurt TL, Petty TL, Genton E. Arrhythmias associated with acute respiratory failure in patients with chronic airway obstruction. Chest 1973; 63: 661-5.

5 Brathwaite D, Weissman C. The new onset of atrial arrhythmias following major noncardiothoracic surgery is associated with increased mortality. Chest 1998; 114: 462-8.

6 Knotzer H, Mayr A, Ulmer H, et al. Tachyarrhythmias in a surgical intensive care unit: a case-controlled epidemiologic study. Intensive Care Med 2000; 26: 908-14.

7 Mayr A, Knotzer H, Pajk W, et al. Risk factors associated with new onset tachyarrhythmias after cardiac surgery-a retrospective analysis. Acta Anaesthesiol Scand 2001; 45: 543-9.

8 Morady F. Radio-frequency ablation as treatment for cardiac arrhythmias. N Engl J Med 1999; 340: 534-44.

9 Ueng KC, Lee SH, Wu DJ, Lin CS, Chang MS, Chen $S A$. Radiofrequency catheter modification of atrioventricular junction in patients with COPD and medically refractory multifocal atrial tachycardia. Chest 2000; 117: 52-9.

10 Prystowsky EN, Benson DW Jr, Fuster V, et al. Management of patients with atrial fibrillation. A statement for healthcare professionals from the subcommittee on electrocardiography and electrophysiology, American Heart Association. Circulation 1996; 93 : 1262-77.

11 ACC/AHA/ESC Guidelines for the management of patients with atrial fibrillation: executive summary. A report of the American College of Cardiology/ American Heart Association Task Force on practice guidelines and the European Society of Cardiology Committee for practice guidelines and policy conferences (committee to develop guidelines for the management of patients with atrial fibrillation). Developed in collaboration with the north American society of pacing and electrophysiology. Circulation 2001; 104: 2118-50.

12 Dusman RE, Stanton MS, Miles WM, et al. Clinical features of amiodarone-induced pulmonary toxicity. Circulation 1990; 82: 51-9.

13 Gleadhill IC, Wise RA, Schonfeld SA, et al. Serial lung function testing in patients treated with amiodarone: a prospective study. Am J Med 1989; 86: 4-10.

14 Singh SN, Fisher SG, Deedwania PC, Rohatgi P, Singh $B N$, Fletcher RD. Pulmonary effect of amiodarone in patients with heart failure. The Congestive Heart Failure-Survival Trial of Antiarrhythmic Therapy (CHF-STAT) Investigators (Veterans Affairs Cooperative Study No. 320). J Am Coll Cardiol 1997; 30: 514-7. 
15 Kaushik S, Hussain A, Clarke P, Lazar HL. Acute pulmonary toxicity after low-dose amiodarone therapy. Ann Thorac Surg 2001; 72: 1760-1.

16 Kharabsheh S, Abendroth CS, Kozak M. Fatal pulmonary toxicity occurring within two weeks of initiation of amiodarone. Am J Cardiol 2002; 89: 896-8.

17 Hill GA, Owens SD. Esmolol in the treatment of multifocal atrial tachycardia. Chest 1992; 101: 1726-8.

18 Balser JR, Martinez EA, Winters BD, et al. B-adrenergic blockade accelerates conversion of postoperative supraventricular tachyarrhythmias. Anesthesiology 1998; 89: 1052-9.

19 Mooss AN, Wurdeman RL, Mohiuddin SM, et al. Esmolol versus diltiazem in the treatment of postoperative atrial fibrillation/atrial flutter after open heart surgery. Am Heart J 2000; 140: 176-80.

20 McCord JK, Borzak S, Davis T, Gheoghiade M. Usefulness of intravenous magnesium for multifocal atrial tachycardia in patients with chronic obstructive pulmonary disease. Am J Cardiol 1998; 81: 91-3.

21 Chiladakis JA, Stathopoulos C, Davlouros P, Manolis AS. Intravenous magnesium sulfate versus diltiazem in paroxysmal atrial fibrillation. Int J Cardiol 2001; 79: 287-91.

22 ECC Guidelines. Part 6: Advanced cardiovascular life support. Section 7: Algorithm approach to ACLS emergencies. Circulation 2000; 102(Suppl I): I136-65.

23 Ellenbogen KA, Dias VC, Plumb VJ, Heywood JT, Mirvis DM. A placebo-controlled trial of continuous intravenous diltiazem infusion for 24-hour heart rate control during atrial fibrillation and atrial flutter: a multicenter study. J Am Coll Cardiol 1991; 18: 891-7.

24 Goldenberg IF, Lewis WR, Dias VC, Heywood JT, Pedersen WR. Intravenous diltiazem for the treatment of patients with atrial fibrillation or flutter and moderate to severe congestive heart failure. Am J Cardiol 1994; 74: 884-9.

25 Delle Karth G, Geppert A, Neunteufl T, et al. Amiodarone versus diltiazem for rate control in critically ill patients with atrial tachyarrhythmias. Crit Care Med 2001; 29: 1149-53.

26 Khand $A U$, Rankin AC, Kaye GC, Cleland JGF. Systematic review of the management of atrial fibrillation in patients with heart failure. Eur Heart J 2000; 21: 614-32. 